\title{
O SENTIDO DO CUIDAR DA CRIANÇA E DA FAMÍLIA NA COMUNIDADE: A EXPERIÊNCIA DA ALUNA DE ENFERMAGEM*
}

\author{
THE MEANING OF CHILD AND FAMILY CARE IN THE \\ COMMUNITY: THE LEARNING EXPERIENCE OF NURSING \\ STUDENT
}

\author{
Myriam Aparecida Mandetta Pettengill** \\ Margareth Angelo***
}

\begin{abstract}
PETTENGILL, M. A. M.; ANGELO, M. O sentido do cuidar da criança e da família na comunidade: a experiência de alunos de enfermagem. Rev.Esc.Enf.USP, v. 34, n. 1, p. 91-8, mar. 2000.
\end{abstract}

\section{RESUMO}

Este estudo, utilizando abordagem fenomenológica, buscou compreender o significado da experiência de aprendizagem da aluna de enfermagem ao cuidar da criança e da familia na comunidade. Os dados foram obtidos por meio de entrevista aberta, individual, tendo como sujeitos nove alunas. Através da análise dos dados emergiram dois temas: ENFRENTANDO O DESAFIO e GERANDO OUTRO OLHAR. A interpretação, segundo o referencial teórico da Análise Existencial de Viktor Frankl, permitiu compreender que o sentido que move a aluna no tema enfrentando o desafio é a busca do conhecimento e o querer fazer algo. Além disso, o estudo permitiu uma reflexão acerca dos componentes da aprendizagem significativa em enfermagem, sendo o tema gerando outro olhar uma conseqüência para o pensar, o sentir e o agir da aluna, favorecendo seu crescimento pessoal e profissional.

PALAVRAS-CHAVE: Enfermagem pediátrica. Ensino. Criança. Família. Estudantes de enfermagem.

\begin{abstract}
This present study, by applying qualitative research under a phenomenological perspective, attemps to seek an understanding of the meaning of the learning experiences of nursing students who care for child and family in the community. The data have been obtained through individual open interviews with nine students. Two' themes have emerged from the analysis of the data: FACING CHALLENGES and GENERATING A NEW VIEW. Applying the theoretical approach of Viktor Frankl's existencial analysis allows us to understand that what mobilizes students when facing challenges is the search for knowledge and desire to do something. Moreover, this study allows a reflection about significant learning in nursing, generating a new view as a consequence to the student feelings, thoughts and actions in the promotion of the personal and professional growth.
\end{abstract}

KEYWORDS: Pediatric nursing. Teaching. Child. Family. Students nursing.

\section{INTRODUÇÃO}

Acreditamos que o ensino de enfermagem é um caminho que possibilita contribuir tanto para elevar a qualidade da assistência prestada aos pacientes e comunidade assistida, como também para a valorização e reconhecimento da profissão.
Por ocasião do desenvolvimento das atividades práticas da disciplina Enfermagem na saúde da criança e do adolescente, oferecida aos alunos de $2^{\circ}$ e $3^{\circ}$ ano de um Curso de Graduação em Enfermagem, era possivel observar que alguns alunos apresentavam dificuldades

\footnotetext{
* Resumo da Dissertação de Mestrado apresentada ao Programa de Pós-graduação da Escola de Enfermagem Universidade de São Paulo, 1998.

** Enfermeira. Professor Assistente do Departamento de Enfermagem da Universidade Federal de Mato Grosso do Sul. Doutoranda do Programa de Pós-graduação da EEUSP. E-mail: jcpettengill@uol.com.br***

*** Enfermeira. Livre Docente, Professor Associado do Departamento de Enfermagem Materno-Infantil e Psiquiátrica da EEUSP. Orientadora.
} 
e até rejeição em atuar na comunidade. Afirmavam que sentiam-se frustrados frente às dificuldades observadas. Outros valorizavam o ensino clínico, em unidades hospitalares, ansiosos por aprender técnicas. Acreditavam saber o que fazer ou pelo menos o que é esperado que o enfermeiro faça; isto é o atendimento curativo, centrado em técnicas. Porém, era possível observar outros alunos que desenvolviam as atividades propostas sem dificuldades, envolvendo-se com as pessoas e realizavam o cuidar em ambas unidades de estágio.

Essas observações afloradas do nosso cotidiano enfermeira-docente,suscitaram alguns questionamentos: por que alguns alunos valorizam mais o cuidar centrado em técnicas, em instituições, tradicionalmente aceitas para o enfermeiro exercer sua prática? Será que o contexto na comunidade, evidenciando os problemas sociais, é um elemento que ameaça e dificulta o aprendizado? Por que alguns alunos conseguem vivenciar uma aprendizagem significativa, tanto em unidades hospitalares quanto na comunidade? Será que são mais sensiveis ao cuidar, não importando o contexto no qual a atividade se realiza?

Tais questionamentos, portanto, motivaram a realização dessa pesquisa, pois compreendendo um pouco mais sobre o significado da experiência de aprendizagem do aluno de enfermagem na comunidade é possivel conhecê-lo melhor, e dessa forma desenvolver o ensino de enfermagem de maneira que lhe proporcione um aprendizado significativo.

ROGERS (1978) conceitua a aprendizagem significativa, como sendo "uma aprendizagem que provoca modificações no indivíduo, em seu modo de pensar, em suas atitudes e em sua personalidade. Permite à pessoa desenvolver-se, atingir autonomia, ser responsável por seu próprio aprendizado e seu futuro profissional e adquirir autoconsciência do processo de aprender".

As leituras realizadas sobre essa abordagem auxiliaram a consolidar algumas crenças a respeito do processo ensino-aprendizagem em enfermagem:

- o primeiro passo para a facilitação aprendizagem é compreender a experiência do outro;

- para realizar o cuidado centrado na pessoa, preocupações, como situações de crescimento. Para aluno precisa aprender o processo de cuidar, mediadompreender o sentido que cada situação propõe, o pelo professor facilitador, na perspectiva humanística; homem lança mão do "órgão do sentido", isto é, sua

- ocorre aprendizagem significativa dconsciência, definida por Frankl como a capacidade que a processo de cuidar quando o aluno desenvolve autonominteligência humana tem de julgar acerca do valor e autoconhecimento;

- para cuidar do outro, o aluno necessita aprender a cuidar de si mesmo e a ser cuidado; experiencia uma á seguir em frente.
Além do sentido vinculado a uma situação

Acreditamos que é importante conhecer as experiências vivenciadas pelos alunos de enfermagem, estão se preparando para cuidar de pessoas, a fim estratégias de ensino, que permitam a formação de profissionais competentes.

Considerando que, alguns alunos, durante a vivência do estágio na comunidade apresentam dificuldades, e que o professor facilitador pode ajudálos, proporcionando condições para uma aprendizagem identidade profissional, buscamos neste estudo: compreender o significado (o sentido) encontrado pelo aluno de enfermagem ao cuidar da criança e da familia na comunidade.

\section{TRAJETÓRIA METODOLÓGICA}

A fenomenologia foi a abordagem metodológica que melhor se aplicava à análise dos dados, pois os dados que pretendiamos obter eram de natureza subjetiva e não quantificáveis estatisticamente. Através dessa realidade vivenciada pelo aluno e desta forma maior compreensão de seu mundo vida.

Considerando a intenção de compreender o sentido que as coisas têm para o aluno em seu processo de aprendizagem, encontramos na Análise Existencial de desenvolvimento deste estudo. Segundo XAUSA (1988), a filosofia preconcebida. É uma posição filosófica solidária com a filosofia existencialista alemã de Heidegger e Jaspers, e apresenta pontos em comum com Marcel, Assim, para análise da existência o método élógico ó que deve ser tomado, pois o revelação de que há a coisa mesma ou o ser em si, sendo o abrir-se e o manifestar-se da própria realidade vivida pelo sujeito

da

O homem, segundo Frankl, pode encontrar moral dos próprios atos (GOMES, 1988;1992).

1rrepetivel e única, há ainda universais de sentido, que se prendem à condição humana e que são chamados valioso, o que acha mais importante para sua vida em
dado momento. Somente a pessoa humana tem consciência do valor e capacidade valorativa, o que varia Viktor Frankl a orientação teórica para o 
em função de processos pessoais internos (FRANKL, 1989a;1991;1992;1994;1996).

Um dos pontos fundamentais da análise existencial é a fé na liberdade, o que caracteriza o homem como ser, portador de uma consciência, dono de seu destino, portanto, chamado a ser responsável. Viktor Frankl vê o homem como um ser incondicionado e livre para fazer escolhas e assumir responsabilidades (GOMES, 1992).

\section{PROCEDIMENTOS DA PESQUISA}

Participaram deste estudo alunos do Curso de Enfermagem de duas Universidades Públicas. Todos os participantes desta pesquisa eram do sexo feminino e estavam cursando, no momento da entrevista, o $4^{\circ}$ ano do Curso de Enfermagem, tendo vivenciado a experiência de aprendizagem em comunidade quando se encontravam entre os $2^{\circ}$ e $3^{\circ}$ anos.

O número de alunas foi definido pelas expressões dos próprios discursos, enquanto foram surgindo dados de interesse obtidos pela convergência das falas. Assim, participaram um total de nove alunas e o único critério preestabelecido foi a aluna ter vivenciado uma experiência de cuidar da criança e da família na comunidade.

Os dados foram coletados através de entrevista aberta e individual. Em um primeiro contato, a aluna foi convidada a fazer parte do estudo, sendo explicado seu objetivo, e, posteriormente, agendado o local, data e hora da entrevista, de acordo com sua preferência. Para nortear a entrevista, foi solicitado a cada uma das alunas que descrevesse uma experiência significativa para sua aprendizagem de enfermagem, na qual tivesse cuidado de uma criança e sua familia na comunidade.

Foi garantido o anonimato das participantes, permitindo que expusessem todas suas impressões durante a vivência da experiência; as entrevistas foram gravadas com a permissão dos sujeitos e, posteriormente, transcritas integralmente. Foi realizada, apenas, uma numeração para facilitar seu processo de análise. As entrevistas foram realizadas entre os meses de Novembro 1997 a Fevereiro de 1998.

Os discursos foram analisados de acordo com o método proposto por FORGHIERI (1989;1993), consistindo em: leitura atenta dos discursos dos sujeitos na busca de Unidades de Significado; identificação das convergências e divergências em cada discurso, agrupando as Unidades de Significado semelhantes em Significado Ampliado; comparação dos Significados Ampliados na busca de elementos comuns, agrupando-os em subtemas e organização dos subterras, visando a emersão dos temas.

\section{RESULTADOS}

O processo de análise, utilizado com vistas à compreensão do significado da experiência de aprendizagem da aluna de enfermagem, ao cuidar da criança e família na comunidade, resultou em dois temas que revelam aspectos da vivência da aluna durante a experiência: ENFRENTANDO O DESAFIO e GERANDO OUTRO OLHAR

Para melhor compreensão dos resultados, os temas são apresentados de forma explicativa, assim como os subtemas que os compõem, incluindo trechos que ilustram o sentido atribuído à experiência para a aluna.

O tema ENFRENTANDO O DESAFIO é gerado pelo desconhecimento que a aluna experiencia, tanto das suas possibilidades quanto das possibilidades do outro, incluindo pessoas e contexto. Tal desconhecimento faz a aluna vivenciar a experiência numa continua busca de conhecimento. Ela segue um movimento, no qual conhece as demandas de cuidado, prepara-se para enfrentá-las, planeja ações, implementa-as e descobre novas possibilidades.

Este tema é melhor compreendido pelos subtemas que o compõem: sentindo insegurança, vivendo sentimentos ambiguos, tendo preconceitos, confrontando-se com a realidade, buscando fortalecer-se para agir, querendo encontrar soluções, fazendo o que é possivel e descobrindo as relações familiares.

Sentindo insegurança significa que a aluna no início da formação é consciente de que é muito nova, e ainda não está suficientemente preparada para cuidar da criança, muito menos da família. Ela quer fazer algo, agir na situação, assumindo responsabilidades e compromissos durante o estágio, porém, ao se aproximar da criança e da família, querendo intervir, vê que não é tão simples, é muito dificil, porque a situação exige conhecimentos e habilidades que ainda não possui. É representado pelos significados: sendo imatura, sem condições para intervir ou mesmo compartilhar de situações que vivencia na comunidade "...porque a gente no segundo ano da faculdade não tinha a mínima noção, nem de identificar, nem de intervir, muito menos de compartilhar ali da família e dar um suporte... "; tendo poucas habilidades, que a faz sentir-se impotente, porque reforça a sensação de ser despreparada "...eu senti assim uma certa impotência de não ter muito conhecimento, muita habilidade para lidar com aquela situação..." e, fazendo poucas coisas, que significa realizar somente aquilo que sente ser capaz nesse momento inicial, restringindo suas ações aos aspectos físicos do cuidado"...quando a gente começou o estágio lá, a gente ia mais para fazer exame físico, a proposta era essa, ia lá fazer exame físico..." 
O subtema vivendo sentimentos ambiguos é provocado pelo despreparo para lidar com as situações. Por um lado, a aluna deseja ir para o campo, para realizar as atividades programadas; por outro lado, é consciente de que possui poucas habilidades e teme as conseqüências das suas ações para a criança e para a familia, apavorando-se com a possibilidade de provocar um problema ainda maior. Sofre, também, pressões tanto dela própria quanto de sua família, e teme ir para a comunidade acreditando que pode pôr em risco sua integridade física. É composto pelas unidades: tendo expectativas e idealizações, pois acredita que encontrará crianças sadias que estarão brincando felizes, pois não estão hospitalizadas, exigindo poucos cuidados "...eu vim com muita vontade de lidar com criança, adoro criança... mas assim adoro criança sadia... ", temendo causar danos à criança e à família "...quando a gente falou e depois veio a resposta que era sífilis, todo mundo ficou abalado, não só eles, a gente pensou que tinha provocado um problema na família , porque... na criança era só mesmo a lesão..." e, temendo ir para a comunidade, pois não havia tido oportunidade de ficar tão próxima de uma favela, sendo uma realidade muito distante da que está acostumada a vivenciar e isso a deixa amedrontada "...quando eu fui para lá eu nunca tinha tido uma experiencia em lidar com a favela e os preconceitos eram muito arraigados em mim, como uma situação de ser violento, de ser um ambiente sujo, de não ser bem recebida.."

Tendo preconceitos ocorre quando a aluna diante da possibilidade de vivenciar a experiência na comunidade percebe emergirem idéias preconcebidas quanto ao local e as pessoas que moram em favela, as quais têm como causa primária justamente seu despreparo para lidar com essas situações. É representado pelos significados: julgando o contexto "..._será por ser de um centro comunitário, é uma favela, com toda carência que existe, tudo mais, será que eles não sofrem maus tratos dos pais. ?"; julgando a capacidade de cuidar da família pois acredita que a criança sofra de maus tratos, acha que a família, sendo carente, morando na favela, não sabe ou não quer cuidar da criança "...a gente pré julgou a família, acho assim, foi o primeiro estágio da gente e a gente já foi com aquela coisa, os pais não estão dando atenção..."

O subtema confrontando-se com a realidade significa que a aluna, enfrentando o desafio como forma de superar seu desconhecimento, tem oportunidade de conhecer os problemas e vulnerabilidades da criança e da família, e a partir daí, planejar suas ações. Ela tem o mundo vivido pelas pessoas da comunidade sendo descortinado diante dos seus olhos. Os significados que o compõe são: sentindo-se atraída pela situação de uma criança, ao estabelecer um contato mais próximo, geralmente com aquela que lhe chama mais sua atenção, porque apresenta problemas de saúde evidentes ao exame físico, ou por empatia "...nós tivemos o caso de uma adolescente de 12 anos que foi muito interessante, ela estava grávida de 6 meses; a mãe e a irmã de 14 anos também estavam grávidas..."; percebendo a vulnerabilidade da criança e da família, pois confronta-se com a realidade social em que a familia vive, compreendendo melhor os motivos pelos quais está mais exposta aos problemas de saúde "..a mãe estava aguardando tratamento na fila de espera da Odonto há um ano..." e ir reconhecendo a falta de informação da família que permite à aluna compreender que, muitas vezes a família não realiza determinados cuidados, ou procura por assistência à saúde por desconhecimento de como acessá-los, contribuindo para aumentar sua vulnerabilidade"...porque ela trabalhava dentro da cidade universitária e não tinha informação nenhuma do que estaria disposto a ela..."

Buscando fortalecer-se para agir é o subtema que revela que o contato mais próximo com a realidade vivida pela criança e sua família, desencadeia na aluna a necessidade de se preparar mais, porque percebe possuir poucas habilidades e conhecimentos. E composto pelos significados: buscando apoio no professor, pois acredita que ele está melhor preparado para lidar com os problemas. A aluna vê o professor como alguém mais experiente, que poderá ajudá-la no enfrentamento da situação, alguém que lhe dará suporte para pensar e agir, assim como para incentivá-la "...chamamos as professoras porque a gente queria fazer uma coisa diferente, ir além..."; buscando fundamentacão teórica como uma maneira de se preparar melhor para enfrentar o desafio, porque sabe que ainda não domina os conhecimentos necessários para cuidar naquela situação "...a gente fez estudo de caso com ela, acompanhamos..." e, buscando conhecer o outro, pois sabe que o conhecimento gerado por essa fonte, pode ajudá-la a esclarecer muitas dúvidas e trazer maior compreensão sobre os problemas evidenciados. Entra em contato com a família, realiza entrevista com as mães, conversa procurando inteirar-se da história de vida e antecedentes pessoais, conhecendo hábitos, querendo entender as razões da situação vivenciada pela criança. Também, realiza visita domiciliar, colocando-se mais próxima do contexto "...então a gente chegou a fazer com ela acho que umas três ou quatro entrevistas pra poder entender a história, tudo...e conversa e ouve as histórias..."

Querendo encontrar soluções revela que a aluna estando mais preparada e fortalecida através dos conhecimentos adquiridos para lidar com a situação, começa a planejar ações que a permitem contribuir na resolução dos problemas evidenciados: Planejando as atividades "...nós_pensamos em montar aulas...então a gente preparou as aulinhas, o material audiovisual para cada faixa etária, a gente começou a trabalhar com as coisas que a gente 
encontrava nesse exame físico ..."; sensibilizando as pessoas envolvidas, aproximando-as e cativandoas para juntas encontrarem soluções para 0 atendimento das demandas de cuidado, pois sabe que sem o apoio dessas pessoas seu trabalho não terá continuidade "...fazer uma reunião com os pais para estar explicando qual era o papel da gente dentro desse centro comunitário; que estariamos fazendo uma avaliação geral das crianças pra tá vendo, problemas de escabiose, pediculose, coisas assim bem gerais para estar dando um retorno pra eles..." buscando recursos na comunidade, indo atrás de informações sobre serviços disponiveis, porque assim poderá planejar as ações de acordo com a realidade vivenciada pela familia: "... tentar conhecer um pouquinho mais sobre como era o dia-a-dia deles, qual era o recurso que eles teriam..." •

O subtema fazendo o que é possivel, significa para a aluna, realizar somente aquilo que reconhece estar ao seu alcance nesse momento da sua formação. Implementando os cuidados junto à criança e à família. A aluna faz exame físico, observa crescimento e desenvolvimento, analisa as necessidades e executa ações, tanto de cuidado direto como educativas, visando à promoção da saúde "...pra gente o mais importante era ensinar aquela mãe, às vezes, a passar um vinagre na cabeça, que era o que ela teria recurso..." e, apoiando as decisões da família "..._a gente apoiou ela ir procurar os recursos..."

Ao interagir com a familia, conhecer suas histórias, crenças e dinâmica familiar, a aluna vai descobrindo as relações familiares, o que permite a ela tomar contato com a realidade da família, suas dificuldades e possibilidades, que se configuram como instrumentos úteis para ajudá-la a enfrentar o desafio de cuidar da criança e da família na comunidade. Este subtema é representado pelos significados: conhecendo a dinâmica familiar, quando a aluna passa a perceber os problemas que afetam os relacionamentos, os quais ela nem sequer imaginava serem possiveis de acontecer, porque são muito diferentes daqueles que está acostumada a vivenciar em seu mundo vida, mas que ao serem reconhecidos poderão contribuir para que tanto ela quanto a família os enfrentem "...ela estava grávida de 6 meses, a mãe também e a irmã de catorze anos também estava grávida... não tinha pai, tinha um padrasto... "; percebendo a rede de apoio na comunidade, a qual através da vizinhança e das relações de amizade que se estabelecem, oferece um suporte à família durante os momentos de dificuldades, principalmente, aqueles relacionados a problemas econômicos "... o padrasto desempregado e a mãe também desempregada; por ocasião da gravidez pediu demissão do serviço...então eles viviam assim de doações, de ajuda dos vizinhos, nossa, do posto de saúde... a gente começou a doar as coisas também..." percebendo o envolvimento da família em relação à saúde de seus membros, e vendo suas motivações e expectativas, provoca na aluna respeito pela familia; acredita ter descoberto mais uma força que a família dispõe para enfrentar seus problemas"...era uma família motivada a querer manter seu ambiente, muito motivada com a saúde da criança e com essa expectativa de ter nascido mais uma criança, eles que já tinham outros dois..." e, observando as reações da família descobre que em algumas ocasiões a mesma não quer se expor, impondo limites para sua aproximação, porque teme ter seu mundo vida invadido. Ela percebe que é importante conhecer e respeitar essas reações familiares, porque só assim poderá entender os problemas e se preparar para buscar soluções "... a criança chegou a faltar até na creche, porque a mãe achou que a gente estava se intrometendo na vida dela...".

O tema GERANDO OUTRO OLHAR emerge quando a aluna, refletindo sobre a experiência vivenciada percebe que os conhecimentos adquiridos ao enfrentar o desafio, são a base de sustentação para as ações que realiza e que repercutem na vida das crianças, na dinâmica familiar e, também, na vida das pessoas envolvidas no cuidado. Ela avalia as transformações nas crianças, familia e contexto e sentese responsável pelas modificações geradas. Isto a faz sentir-se realizada, e proporciona modificações no seu modo de pensar, sentir e agir em enfermagem.

Este tema é composto pelos subtemas: sentindo satisfação com os resultados, modificando sua maneira de pensar, despertando sentimentos positivos, comprometendo-se com a criança e a familia e ampliando a visão do papel profissional

Sentindo satisfação com os resultados é quando a aluna percebe que as ações que realiza são adequadas e contribuem para a solução dos problemas da criança e de sua família naquele momento. Este subtema é composto pelas unidades: refletindo sobre as accões realizadas "...graças a Deus deu tudo certo, depois foi até melhor porque de repente tinha trazido coisas, teria sido pior no futuro para eles..." sendo bem recebida pela familia, é o que faz a aluna sentir-se feliz e motivada para dar continuidade às suas ações, pois reconhece o fortalecimento do vínculo que estabelece com a criança e a família "... o respeito que eles tinham conosco, nós entrávamos às vezes na casa deles e eles nos recebiam bem ..." vendo a repercussão na família, quando a aluna passa a acreditar que suas ações contribuem para ampliar as possibilidades da família, uma vez que reforçam sua capacidade para enfrentar e superar os próprios problemas "... você vê que assim é pura e simplesmente o poder de informação, que a pessoa não tem e que se você leva, ela vai atrás..."; vendo a resposta das crianças, a aluna passa a atribuir à atuação conjunta (sua e da família) a melhora das condições gerais de saúde das crianças assistidas, servindo de estímulo para 
continuar seu trabalho "...foi todo um trabalho de conscientização dessa mãe, trabalhamos com ela, essa criança foi melhorando... a escabiose que ela apresentava também melhorou, foi todo um trabalho assim que foi progredindo aos poucos..."

Modificando sua maneira de pensar significa que a aluna percebe que nem tudo que havia julgado é verdadeiro, e tem oportunidade para repensar idéias preconcebidas, modificando sua maneira de ver o ambiente e partilhando experiências. O subtema é representado pelos significados: revendo preconceitos "...acho que a pior besteira que a gente faz na nossa área é começar a pré julgar antes de saber o que que tá acontecendo... "; vendo vantagens no cuidado na comunidade, porque se percebe mais próxima da realidade vivida pela família, o que lhe dá oportunidade de adquirir mais conhecimento da situação, facilitando sua compreensão das demandas da criança, família e ambiente "...na favela você vê, você está conseguindo fazer alguma coisa, mesmo que seja pequena ...já no hospital você está mais distante de ver como ela está vivendo... você não sabe se aquela orientação que você está dando vai conviver com a realidade dela, por mais que ela fale não é a mesma coisa que você estar lá... "; compartilhando a experiência, pois espera que através do relato de sua vivência possa estimular outras pessoas a enfrentar o desafio. Dependendo do apoio que recebe do professor, vê sua prática valorizada, torna-se mais estimulada até para divulgar seu trabalho, expondo seus sentimentos, pensamentos e ações, realizadas durante o processo "...o departamento inteiro ficou sabendo da nossa interação com ela, foi motivo até para estar fazendo relato de experiência em um congresso..."

A experiência provoca na aluna modificações, também, em seus sentimentos, porque se sente gratificada e valorizada pela aceitação do seu trabalho, despertando sentimentos positivos. No início de seu ensino prático, vivencia sentimentos ambíguos decorrentes de seu despreparo. Enfrentando o desafio, ou seja, ampliando conhecimentos e implementando ações que a conduzam a resultados satisfatórios, percebe que a criança e família a respeitam e gostam de seu trabalho, sentindo-se valorizada "...o_respeito que eles tinham para com a equipe de saúde chegou a me sensibilizar..." despertando-lhe alegria, porque percebe que suas ações contribuem para a melhora no estado de saúde da criança e das conquistas da família "...ao mesmo tempo a gente fica muito contente de ter visto esse crescente dela, porque ela parou com a crise de pneumonia..."; sentindo a realização pessoal. pois ter um relacionamento gratificante com a criança, e fazer algo pela família, torna a aluna satisfeita e realizada "...mas eu gostei, você se sente importante naquele momento, você sentia* que era importante e que para elas

também era importante..." porém, também sentindo tristeza, porque tem contato com uma realidade social que desconhecia, que não a deixa ficar imune ao sofrimento do outro, provocando sentimento de compaixão pela criança e família ... a gente fica receosa, às vezes, sai deprimida vendo uma criança mal..."

O subtema comprometendo-se com a criança e a familia resulta por sentir-se aceita e valorizada pela família, tornando-se cada vez mais envolvida no contexto. Percebe que isso lhe facilita alcançar seu objetivo de ajudar à família a superar seus problemas. Tendo relação envolvente cria laços com a família, tornando-se alguém significativo, disponivel a ouvir e ajudar na solução dos problemas "... nós iamos lá, nós não éramos as acadêmicas, nós éramos as amigas dela também, com quem ela conversava, com quem ela mostrava as bonecas que ainda tinha..."; valorizando a pessoa,_seus conhecimentos e atitudes transmite a elas o sentimento de ser importante, porque se preocupa com seus problemas "...ela já tinha experiência de maternidade e poderia estar ensinando pra gente, através de sua experiência como lidar com a criança..."; colocando-se no lugar da pessoa, analisando os problemas sob o prisma de quem os está vivenciando e propondo ações que gostaria que fizessem com ela, caso estivesse na mesma situação "...porque eu já sou mãe, já tive filhos e sei dessa preocupação na fase final da gestação, como isto gera uma tensão pra você..." percebendo o crescimento do outro reforça o comprometimento da aluna para com a criança e a família, pois pode observar os progressos alcançados pela pessoa, provocados através de suas intervenções "... ela foi crescendo, a gente sentiu um crescimento nela, ...conforme a gente ia esclarecendo com essas visitas, o que ela poderia estar fazendo pra essas crianças e mesmo assim para ela própria..."

\section{Ampliando a visão do papel profissional é} outra conseqüência de importância, o que leva a aluna perceber que ser enfermeiro é ir além da prestação de cuidados fisicos ou realização de procedimentos técnicos; significa atuar em conjunto com a familia, buscando ações capazes de solucionar as demandas de cuidado. Percebe que o enfermeiro tem um papel social importante, nem sempre contemplado no curso. Percebendo o crescimento pessoal, porque ao vivenciar uma experiência significativa, gerando um outro olhar para a enfermagem, sente-se enriquecida e mais amadurecida "...eu acho que pra mim foi um crescimento muito grande no sentido de que você tem que saber um pouco mais..." tendo vantagens, porque tem oportunidade de aprender muito através do envolvimento com a família "...nós tivemos muito mais vantagens, assim no meu ver, pelo menos na minha contribuição naquele momento...porque foi enriquecedor, nós entrávamos na casa deles, eles nos recebiam bem, a gente. interferia na vida deles,

sem ver o todo..." sendo marcante, pois lhe permitiu 
um crescimento interno e transformou seu modo de pensar e fazer enfermagem ".. foi muito interessante uma coisa que eu nunca esqueço... ". A aluna torna-se predisposta a trabalhar com a familia, sendo sensibilizada para "estar com" a familia, porque percebe que planejando os cuidados em conjunto tem seu apoio e mais chances de sucesso "...tentando planejar uma assistência junto para essa mãe, para essa família, para essa criança...". Reconhece, também, que não basta só curar a doença, sendo sensibilizada para "ir além" do enfoque na patologia, porque só assim será possivel ver a pessoa inteira e propor ações para assisti-la de forma integral, contemplando não apenas o biológico, mas também, seus sentimentos e emoções "...me fez abrir horizontes, vai além do patológico, tem uma coisa muito de você compreender a inserção social, contexto econômico... muito além disso...". A experiência transforma a maneira como a aluna percebe a atuação do enfermeiro, sendo sensibilizada para o papel social do enfermeiro, porque observa que as crianças e as famílias esperam mais do que cuidados fisicos do enfermeiro, querem ser compreendidas e ajudadas na busca de soluções para seus problemas emocionais, afetivos, sociais, econômicos, entre outros "... o enfermeiro tem um papel mais amplo, não é um papel só de cuidado à saúde mas um papel social....nós temos que ter uma visão mais ampla das pessoas, verificar o psicológico, entender ela, compreender.."

\section{DISCUSSÃO}

O exercício de compreensão realizado permitiu-nos identificar no significado da experiência de aprendizagem da aluna com a criança e a família, conceitos presentes na proposição de Viktor Frankl, dentre os quais destacam-se a liberdade e a responsabilidade.

A aluna movimenta-se na busca de sentido para sua prática, fazendo escolhas que são frutos da intencionalidade de sua consciência. $\mathrm{O}$ sentido extraído nesse momento da sua vivência é a força motivadora que direciona suas ações, revelando o caráter incondicionado do homem, que mesmo frente a todas as dificuldades, não se acomoda e busca superá-las através de atitude livre, consciente e responsável. Não se trata de injetar sentido nas coisas, mas sim, de extrair o sentido delas, de captar o sentido de cada uma das situações com que nos defrontamos (FRANKL, 1989b;1992).

É essa atitude responsável, com sentido, que faz a aluna assumir a direção de seus atos, ENFRENTANDO O DESAFIO, sendo útil, autotranscendendo-se, isto é, colocando-se a serviço de pessoas e de uma causa (FRANKL;1989a).
A busca de conhecimento e o querer fazer algo, configuram-se como sentido para a aluna enfrentar o desafio, superando o desconhecimento, a insegurança e os preconceitos, e direcionando suas atividades de aprendizagem. Sente-se cada vez mais motivada, construindo seu caminho através das suas intenções, tendo um sentido, uma finalidade clara, um para quê (LUKAS, 1990).

O sentido para agir na situação levando-a a assumir de forma responsável as ações, proporcionalhe crescimento interno, tornando-a equipada e com recursos para realizar seu vir-a-ser, sua missão. Ela movimenta-se entre o que é e o que deveria ser.

A experiência é significativa para sua aprendizagem, porque lhe permite desenvolver-se como pessoa, com autonomia, transformando seu modo de ser, sentir, pensar e agir em enfermagem, GERANDO OUTRO OLHAR.

É possivel apreender que a cada etapa vivida na experiência, a aluna extrai um sentido, uma possibilidade que the permite direcionar suas atitudes. Esses sentidos concretos que surgem a cada momento são responsáveis pelo seu engajamento na situação, e, talvez, até lhe possibilitem que realize uma missão plena de significados para seu futuro.

\section{REFLEXÕES}

A realização desta investigação possibilitou o desencadeamento de reflexões, levando à compreensão do quanto pode ser complexo o processo de aprendizagem. Buscávamos compreender o significado da experiência de aprendizagem para a aluna de enfermagem ao cuidar da criança e da família na comunidade. Pela análise dos relatos das vivências das alunas nos foi possivel compreender alguns aspectos da aprendizagem, que contribuíram para modificar a maneira de se olhar para a aluna, revendo preconceitos e atitudes preconcebidas, tornando-se um aprendizado significativo.

Buscávamos, também, apreender em que consistia uma aprendizagem significativa para a aluna no contexto da comunidade, e a partir deste estudo ficou claro o que ROGERS (1978) entende por aprendizagem significativa. De posse dos resultados encontrados neste estudo nos é possivel afirmar que a experiência vivenciada pela aluna contempla os componentes de uma aprendizagem libertadora, concebida por Rogers.

Percebemos que a experiência de aprendizagem significativa que ocorre no início da formação profissional, estando a aluna mais aberta às possibilidades de sentido, parece facilitar o despertar de um engajamento compromissado não apenas com a comunidade, mas com a profissão, aspecto também observado por ANGELO (1989) em seu estudo. 
Percebemos, também, que a busca de conhecimento sendo mediada pelo professor facilitador, oferece maiores oportunidades para a aluna realizar a aprendizagem significativa, pois ela se sente ajudada, o que lhe dá segurança para mergulhar integralmente na experiência, ampliando suas possibilidades de cuidar, modificando seu olhar, seu pensar, sentir e agir na profissão. Aspecto explorado por ANGELO (1989), enfatizando que a experiência da aluna pode ser mais positiva quanto mais acolhedor for o contexto onde se realiza a aprendizagem prática.

A inter-relação da aluna com a criança e a família favorece, também, a aprendizagem significativa, pois aproxima a aluna do contexto de vida da pessoa, ampliando seu conhecimento e atendendo as demandas de cuidado em uma relação envolvente e comprometida, promovendo tanto seu crescimento pessoal, quanto o do outro.

Embora tenhamos compreendido sobre o processo de aprendizagem significativa, contudo ainda nos restam alguns questionamentos, sobretudo, quando a aluna não vivencia a experiência dessa maneira. Considerando-se que não se pode colocar sentido nas coisas, como é possivel o professor ajudá-la a transformar seu olhar, a extrair sentido das situações e transformar a experiência em aprendizagem significativa?

LUKAS (1992), discipula de Viktor Frankl, afirma que é possivel realizar uma educação para o sentido, bastando ao professor comprometer-se com essa maneira de ensinar. Ressalta que se trata de aperfeiçoamento da consciência, em que ao mesmo tempo que se transmite conhecimento, desenvolve-se a cultura e desperta o engajamento. Essa autora faz uma proposta de educação, contemplando a experiência de sentido, que consiste em uma primeira etapa explicar ao educando que para uma vida plena de sentido há necessidade de conhecer as realizações prévias, isto é, permitir ao educando que perceba as possibilidades de sentido, que poderão vir a surgir, através da sua profissão, por exemplo. A segunda etapa consiste em auxiliar o educando a perceber as configurações de sentido existentes nas situações, aperfeiçoando a capacidade de percepção de possibilidades. A terceira etapa consiste em aproveitar o que foi percebido, concretizando a "vontade de sentido", dizendo internamente "sim" ao sentido da situação.

Todos nós, envolvidos com o processo de ensino, precisamos fazer escolhas sobre a maneira de ensinar. Cabe relembrar o que ANGELO (1993) recomenda: "cada um de nós é livre para escolher, inclusive ferramentas de trabalho. Neste processo de escolha é importante que estejamos alertas, pois podemos decidir por aquelas que oprimem, mas também, optar por outras que liberem."

Existe muito ainda a ser pensado e realizado sobre o educar para o sentido no âmbito da enfermagem. Mas é preciso finalizar, considerando oportuno apresentar o pensamento de LUKAS (1992), o qual partilhamos, e que poderá despertar o sentido de ensinar para os professores: "daria a todos aqueles que lutam em prol da humanização nas escolas e famílias o seguinte conselho: ensinem novamente às crianças a dedicação a algo, o engajamento a favor de algo, a confiança em algo, e tentem imunizá-las contra as correntes pessimistas atualmente vigentes, das quais emerge a concepção resignada de que tudo é inútil e supérfluo".

\section{REFERÊNCIAS BIBLIOGRÁFICAS}

ANGELO, M. Vivendo uma prova de fogo: as experiências iniciais da aluna de enfermagem. São Paulo,1989. 133 p. Tese (Doutorado)-Instituto de Psicologia, Universidade São Paulo.

e do adolescente: politicas e programas de saúde- aspectos técnicos, científicos e éticos. Sessões Simultâneas. In: CONGRESSO BRASILEIRO DE ENFERMAGEM, 45. Recife, 1993. Anais. Recife, ABEn-Seção PE, 1993. p.127-31.

FRANKL, V. E. Psicoterapia e sentido da vida: fundamentos da logoterapia e análise existencial. São Paulo, Quadrante, 1989a

Sede de sentido. São Paulo, Quadrante, 1989b.

Psicoterapia para todos: uma psicoterapia coletiva para contrapor-se a neurose coletiva. Petrópolis, Vozes, 1991.p 11-21: 0 homem em busca do sentido.

Argumentos em favor de um otimismo trágico. In: FRANKL, V.E. et al. Dar sentido à vida: a logoterapia de Frankl. 2. ed. Petrópolis, Vozes, 1992.

La voluntad de sentido. 3. ed. Barcelona, Herder,1994. Herder, 1996.

E1 hombre en busca de sentido. 18.ed. Barcelona FORGHIERI,Y.C. Contribuição da fenomenologia para o estudo das vivências. Rev. Bras. Pesq. Psicol., v.2, n.1, p.7-29, 1989.

Psicologia fenomenológica: fundamentos, método e pesquisas. São Paulo, Pioneiras, 1993.

GOMES, J.C.V. A prática da psicoterapia existencial: logoterapia. Petrópolis, Vozes, 1988.

Logoterapia: a psicoterapia existencial humanista de Viktor Emil Frankl. São Paulo, Loyola, 1992.

LUKAS, E. Mentalização e saúde: a arte de viver a logoterapia. Petrópolis, Vozes, 1990. p.68-84: Objetivos da educação do ponto de vista da logoterapia.

Prevenção psicológica: a prevenção de crises e a proteção do mundo interior do ponto de vista da logoterapia. Petrópolis, Vozes, 1992. p. 241- 55: Educar com sentido hoje.

ROGERS, C.R. Liberdade para aprender. 4.ed. Belo Horizonte, Interlivros, 1978.

XAUSA, I.A.M. A psicologia do sentido da vida. 2.ed. Petrópolis, Vozes, 1988. 